\title{
Pediatric Pharyngeal IgD-positive Monoclonal Plasmacytoid and Plasma Cell Neoplasm
}

Summary: Pediatric neoplasm with monoclonal proliferation of lymphoplasmacytoid lymphocytes and plasma cells is exceedingly rare and has essentially never been reported in immunocompetent children. Here, we report a previously healthy 13 -year-old girl with a pharyngeal mass and enlarged cervical lymph nodes. The pharyngeal mass was composed of $\mathrm{CD} 138^{+}, \mathrm{CD}_{79 \mathrm{a}^{+}}, \mathrm{MUM}^{-1}{ }^{+}, \mathrm{IgD}^{+}$, $\mathrm{CD} 20^{-}, \mathrm{PAX}_{-}^{-} 5^{-}, \mathrm{CD} 43^{-}, \lambda$-restricted monoclonal plasmacytoid, and plasma cells. Scattered CD20 ${ }^{+}, \mathrm{PAX}-5^{+} \mathrm{B}$ cells were present in the background. The patient was treated as localized non-Hodgkin lymphoma (stage II) with cyclophosphamide, doxorubicin, vincristine, and prednisone and is in complete remission at 17 months from the last chemotherapy.

Key Words: immunocompetent children, neoplasm, lymphoplasmacytoid lymphocytes, plasma cells, immunoglobulin D positive

\section{(J Pediatr Hematol Oncol 2015;00:000-000)}

Pedia diatric non-Hodgkin B-cell lymphoma mainly includes Burkitt lymphoma and diffuse large B-cell lymphoma. ${ }^{1}$ Indolent B-cell lymphoma in children is uncommon and is mainly comprised of marginal zone lymphoma (MZL) and 35 follicular lymphoma. ${ }^{2,3}$ Pediatric MZL, unlike MZL in the adult population, predominantly includes nodal MZL.,5

37 Extranodal MZL in children has rarely been reported and involved sites include the gastrointestinal tract, skin, orbits, 39 salivary glands, tonsils, adenoids, appendix, lung, breast, and thymus. ${ }^{49}$ Other types of pediatric non-Hodgkin B-cell 41 lymphoma, such as lymphoplasmacytic lymphoma (LPL) and plasma cell neoplasm (PCN), are exceedingly rare. ${ }^{6,10-12}$

43 Here, we report a neoplasm composed of predominantly immunoglobulin (Ig)D-positive monoclonal plasmacytoid 45 and plasma cells in an immunocompetent 13-year-old girl 47 with pharyngeal mass and cervical lymphadenopathy.

\section{CASE REPORT}

A 13-year-old girl with a history of tonsillectomy at age 3 noticed an abnormal mass in her throat with occasional pain. Physical examination revealed a submucosal linear mass measuring

Received for publication January 16, 2014; accepted February 24, 2015. From the *Department of Pathology and Laboratory Medicine, Indiana University School of Medicine; and †Department of Pediatric Hematology and Oncology, Riley Hospital for Children, Indiana University Health, Indianapolis, IN

The authors declare no conflict of interest. Laboratory Medicine, Indiana University School of Medicine, 350 West 11th Street, Room 5042, Indianapolis, IN 46202 (e-mail: sz5@iupui.edu).

Supplemental Digital Content is available for this article. Direct URL citations appear in the printed text and are provided in the HTML and PDF versions of this article on the journal's Website, www. jpho-online.com.

Copyright (C) 2015 Wolters Kluwer Health, Inc. All rights reserved.

J Pediatr Hematol Oncol • Volume 00, Number 00,
Reprints: Shanxiang Zhang, MD, PhD, Department of Pathology and
$4 \times 1 \mathrm{~cm}$, located in right posterior oropharynx near the old tonsil fossa. An ENT physician at an outside institution performed an excisional biopsy of the mass. Upon pathology report from that institution she was referred to our tertiary care center [Indiana University Health (IUH)] for further evaluation. She had no fever, night sweats, or weight loss. Her past medical history was otherwise unremarkable. Her family medical history included cervical cancer in her maternal grandmother, thyroid cancers in the sister and niece of her maternal grandmother, and lymphoma (type unknown) in her paternal grandfather. There was no family history of immunodeficiency. A whole body computed tomography and positronemission tomography scan revealed enlarged, bilateral, hypermetabolic, level II cervical lymph nodes, abnormal fullness, and intense metabolic activity in the lymphoid tissue in the tongue base, oropharynx, and nasopharynx. There was no evidence of metastatic disease outside of the neck. Her blood analysis showed normal complete blood count (white blood cells: $7.0 \mathrm{k} / \mathrm{mm}^{3}$, reference: 4.5 to $11.5 \mathrm{k} / \mathrm{mm}^{3}$; hemoglobin: $13.4 \mathrm{~g} / \mathrm{dL}$, reference: 12 to $15 \mathrm{~g} / \mathrm{dL}$; platelet: $195 \mathrm{k} / \mathrm{mm}^{3}$, reference: 150 to $450 \mathrm{k} / \mathrm{mm}^{3}$ ) and differential (56\% neutrophils, 33\% lymphocytes, and $9 \%$ monocytes), normal liver/renal functions, normal lactate dehydrogenase (162 U/L, reference: 100 to $242 \mathrm{U} / \mathrm{L})$, and normal uric acid $(5.4 \mathrm{mg} /$ $\mathrm{dL}$, reference: 2 to $7 \mathrm{mg} / \mathrm{dL}$ ).

Review of the excisional biopsy at IUH revealed histologically unremarkable squamous mucosa overlying marked proliferation of predominantly plasmacytoid lymphocytes and plasma cells. There were few scattered and rare aggregates of small lymphocytes (Fig. 1A). Few residual salivary glands and rare follicles with germinal centers were noted. Immunohistochemical stains (Figs. 1B-H) performed at IUH showed the great majority of cells to be positive for CD79a, CD138, VS38, MUM-1, IgD, $\lambda$ light chain, and negative for CD3, CD20, PAX-5, CD5, CD10, CD23, CD43, cyclin D1, SOX11, BCL-6, CD56, CD117, CD123, $\kappa$ light chain, IgG, IgA, IgM, and $\mathrm{S}-100$. The proliferative index as revealed by $\mathrm{Ki}-67$ stain was low $(<10 \%)$. There were few $\mathrm{CD} 20^{+}$ and/or PAX $-5^{+}$B cells in the background. CD21 and CD23 stains revealed rare follicular dendritic cell meshworks. Viral stain for HHV8 and in situ hybridization for Epstein-Barr virus-encoded RNAs (EBER) were negative. Per pathology report from AmeriPath Indiana (Indianapolis, Indiana), flow cytometric analysis (FCA) revealed a low-viability (approximately 25\%) sample with few polyclonal B cells and immunophenotypically unremarkable $\mathrm{T}$ cells (markers tested: CD3, CD4, CD5, CD7, CD8, CD10, CD19, CD20, CD23, CD 38, CD45, CD56, FMC7, sKappa, and sLambda). No FCA for plasma cells was performed. Fluorescence in situ hybridization performed at IUH revealed no $A P I / M A L T 1$ fusion or copy number changes of $A P 1$ and $M A L T 1$ genes. Molecular study with multiplex PCR performed at IUH showed clonal Ig heavy chain $\gamma$ rearrangement (Fig. 2). No cytogenetic/ karyotyping study was performed at either outside or our own institute. A descriptive diagnosis of monoclonal plasmacytoid and PCN, most compatible with extranodal MZL of mucosa-associated lymphoid tissue (MALT lymphoma) with plasmacytic differentiation was rendered. Subsequent bilateral bone marrow examinations performed at IUH revealed few scattered $\lambda$-predominant plasmacytoid/plasma cells (supplemental Fig. 1, Supplemental Digital Content 1, http://links.lww.com/JPHO/A91, http://links.lww. com/JPHO/A92, http://links.lww.com/JPHO/A93, http://links. lww.com/JPHO/A94, http://links.lww.com/JPHO/A95). Molecular study of the bone marrow aspirate with multiplex PCR performed at www.jpho-online.com | 1 
1

3
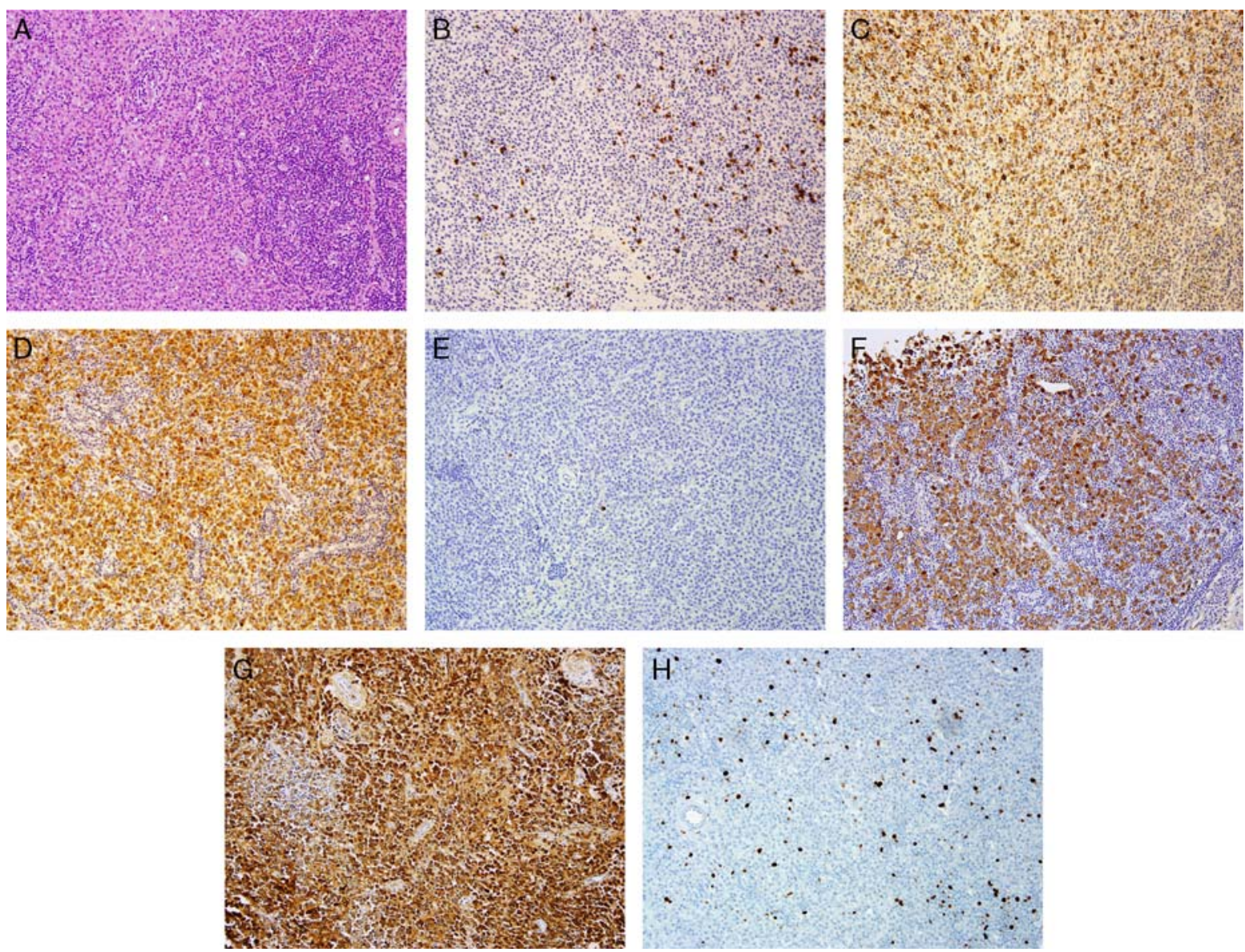

FIGURE 1. Morphologic and immunophenotypical features of pharyngeal mass. A, Hematoxylin and eosin, magnification: $\times 200$. B-H, Immunohistochemistry, magnification: $\times 200$. B, CD20; C, CD138: D, CD79a; E, kappa; F, lambda; G, IgD; H, Ki-67.

IUH revealed no clonal Ig heavy chain $\gamma$ rearrangement (data not shown).

As pediatric MALT lymphoma has been reported in immunodeficient patients and gastric MALT lymphoma is associated with Helicobacter pylori $(H$. pylori) infection, the patient was evaluated for T-cell and B-cell subsets, Ig levels including IgG with subclasses IgA, IgM, and IgE, HIV, hepatitis panel, and H. pylori infection. There was a borderline increase in her serum IgG antibody $(1.03$, reference range: $<0.75)$ against $H$. pylori. The patient had normal serum levels of $\operatorname{IgA}(112 \mathrm{mg} / \mathrm{dL}$, reference: 47 to $317 \mathrm{mg} / \mathrm{dL}), \operatorname{IgM}(72 \mathrm{mg} / \mathrm{dL}$, reference: 56 to $242 \mathrm{mg} / \mathrm{dL}), \operatorname{IgE}$ $(14 \mathrm{kU} / \mathrm{L}$, reference: 2 to $114 \mathrm{kU} / \mathrm{L})$, and $\operatorname{IgG}(838 \mathrm{mg} / \mathrm{dL}$, reference: 680 to $1531 \mathrm{mg} / \mathrm{dL})$ including its subclasses. B-cell $\left(355 / \mathrm{mm}^{3}\right.$, reference 200 to $\left.1259 / \mathrm{mm}^{3}\right)$ and T-cell $\left(1524 / \mathrm{mm}^{3}\right.$, reference: 1072 to $3890 / \mathrm{mm}^{3}$ ) counts and their subsets were within normal reference range. Serum studies for hepatitis A, B, C, and HIV were all negative. There was no monoclonal protein by serum protein electrophoresis test.

The patient was treated as stage II non-Hodgkin lymphoma (NHL) per POG9219 protocol (https://members.childrensoncology group.org/prot/ProtInfo.asp?ProtocolNum $=9219 \&$ Disease $=$ NHL) A 6-week induction phase included vincristine $1.5 \mathrm{mg} / \mathrm{m}^{2}$ weekly for 6 doses, doxorubicin $40 \mathrm{mg} / \mathrm{m}^{2}$ and cyclophosphamide $750 \mathrm{mg} / \mathrm{m}^{2}$ on days 1 and 22, respectively, and prednisone $40 \mathrm{mg} / \mathrm{m}^{2} / \mathrm{d}$ for 28 days. This was followed by a shorter consolidation phase consisting of a single dose each of vincristine $1.5 \mathrm{mg} / \mathrm{m}^{2}$, doxorubicin $40 \mathrm{mg} / \mathrm{m}^{2}$, and cyclophosphamide $750 \mathrm{mg} / \mathrm{m}^{2}$ along with 5 days of prednisone $40 \mathrm{mg} / \mathrm{m}^{2} / \mathrm{d}$. She was also treated with lansoprazole, amoxicillin, and clarithromycin for $H$. pylori due to positive H. pylori IgG antibody. Her postchemotherapy computed tomography and positron-emission tomography scan performed 1 week after completing chemotherapy revealed resolution of previous disease. Since that time she has been followed clinically and is currently in complete remission at 17 months from her last chemotherapy.

\section{DISCUSSION}

Small B-cell lymphoma with plasmacytic differentiation is used to describe a neoplasm of small B cells, plasmacytoid lymphocytes, and plasma cells. The major differential diagnosis includes MZL with plasmacytic differentiation and LPL. ${ }^{13}$ In the pediatric population, MZL has been rarely reported including MZL with plasmacytic differentiation. However, essentially all the reported MZL cases contained aggregates and sheets of CD20 ${ }^{+}$B cells. ${ }^{3,5}$ Pediatric MZL tends to be IgD-negative and presents with localized disease (stage I). ${ }^{5}$ The lesion in our case involved the patient's oropharynx and cervical lymph nodes (stage II). Histologically, the lesion was composed of sheets of IgD-positive, $\lambda$-restricted monoclonal plasmacytoid lymphocytes and/or plasma cells. There were rare follicles as indicated by CD21 and CD23 stains. CD20 and PAX-5 stains revealed few $\mathrm{B}$ cells. The $\mathrm{B}$ cells were shown to be polyclonal by FCA, although the viability of the sample was very low (approximately 25\%). The few B cells in our case were $\mathrm{CD}^{4} 3^{-}$, although the $\mathrm{B}$ cells in the reported pediatric MZL tend to be $\mathrm{CD} 43^{+}$. There were no background progressive transformed germinal centers as 


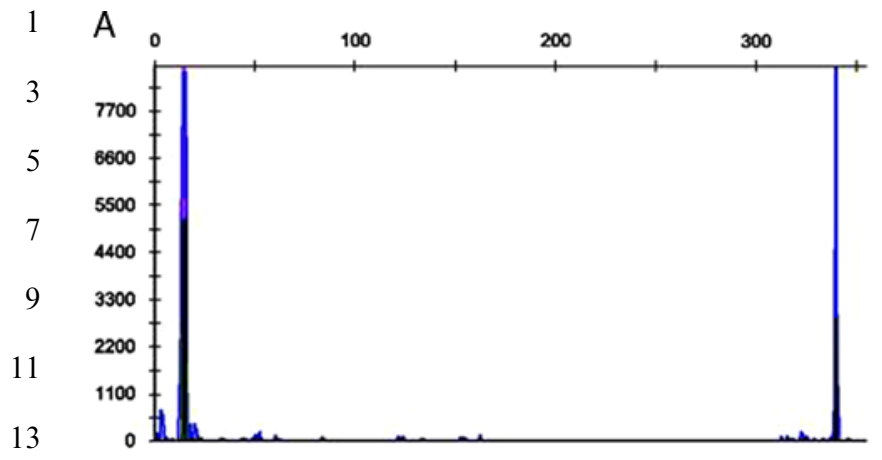

15 and lymphoepithelial lesions as commonly seen in extranodal MZL. ${ }^{5}$ The molecular test (PCR) demonstrated clonal Ig heavy chain $\gamma$ gene rearrangements, which supported a clonal neoplastic process. Overall we favor this lesion to be a B-cell lymphoma with extreme plasmacytic differentiation, although the presence of few CD43- B cells added the difficulty of recognizing this case as a B-cell neoplasm.

LPL is essentially an adult disease. ${ }^{13}$ To our knowledge there were only 2 reported pediatric cases of LPL/ LPL-like lesions which were both associated with WiskottAldrich syndrome and were self-limited. ${ }^{12,14}$ Our patient did not have any history of recurrent infections and workup for possible immunodeficiency was negative. Similarly, PCN is exceedingly rare in children and is by current World Health Organization definition a neoplasm secreting heavy chain class-switched Ig. ${ }^{15}$ Morphologically, however, our case was most compatible with LPL or PCN. As pediatric LPL and PCN are either extremely rare or have not been widely accepted in literature, and LPL in adults is typically IgD-negative, we were hesitant to render a diagnosis of LPL or PCN for this lesion.

Plasmablastic lymphoma (PBL) is a diffuse proliferation of large neoplastic cells which morphologically resemble B immunoblasts, but with the immunophenotype of plasma cells. The tumor cells are positive for CD138, CD38, VS38c, MUM-1, CD79 (majority), and are negative or only weakly positive for CD45, CD20, and PAX-5. The Epstein-Barr virus study (EBER) is commonly positive. PBL is an aggressive lymphoma typically with a high proliferation fraction. Patients with PBL usually have advanced disease (stage III or IV) and die within the first year after diagnosis. ${ }^{16}$ Although it is most commonly seen in HIV-positive individuals, PBL has been reported in immunocompetent individuals. However, almost all PBL reported in immunocompetent individuals is seen in adults, whereas pediatric PBL is reported only in HIV-positive children. ${ }^{17-19}$ Our
TABLE 1. Comparison of Marginal Zone Lymphoma, Lymphoplasmacytic Lymphoma, and Plasmablastic Lymphoma in Pediatric Population

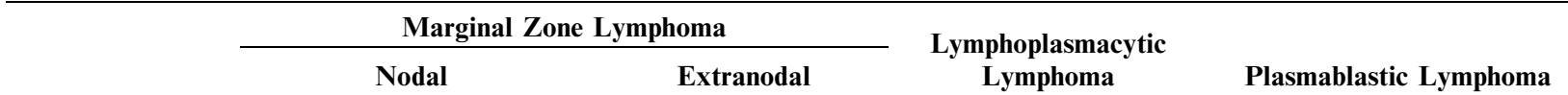

Common affected Head and neck LN, lymphoid Ocular adnexa, salivary sites

Pathologic description

tissue

Small to intermediate glands, skin lymphocytes with scattered plasma cells, marginal zone expansion, PTGC features

Monocytoid cells, plasma cells, lymphoepithelial lesions, architectural distortion

Immunophenotype $\mathrm{CD} 20^{+}, \mathrm{CD} 43^{+}$

$$
(\sim 70 \%), \mathrm{CD}^{-} \text {, }
$$$$
\text { CD10-, BCL-6 }{ }^{-}
$$

Associated features

Predominantly male; stage I, rarely II, III

Molecular markers Few trisomies 18, 3

Treatment

Excision, CT, RT

Outcome/survival Excellent
Few with autoimmune disease; Helicobacter pylori in gastric MZL; stage I, rarely II, III

Rare trisomy 3, IGH$M A L T 1$, tetraploidy RT, CT, excision

Excellent
Head and neck, skin lymphadenopathy

Numerous plasma cells with scattered small lymphocytes

$\mathrm{CD} 138^{+}$and $\mathrm{IgG}+$ plasma cells and $\mathrm{CD} 20^{+}, \mathrm{CD}^{-}$, $\mathrm{CD} 10^{-}, \mathrm{CD}^{-} 3^{-} \mathrm{B}$ cells

Wiskott-Aldrich syndrome and 1 case also with Von Recklinghausen

Unknown

None

Self-limited neurofibromatosis
Large plasmablastic cells with conspicuous nucleoli and basophilic cytoplasm, sheetlike or nest-like growth pattern

CD45 ${ }^{+} / \mathrm{CD}^{2} 5^{-}, \mathrm{CD} 20^{-}$, $\mathrm{VS} 38 \mathrm{c}+, \mathrm{MUM}^{+}{ }^{+}$,

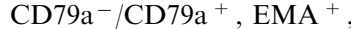
$\mathrm{EBER}^{+}, \mathrm{CD}^{-} 6^{-}, \mathrm{Ki}-67$ high $(>75 \%)$

More males; predominantly $\mathrm{HIV}+$; stage III and IV, rarely II

Possible t( $8 ; 14), I G H / M Y C$

HAART, HARRT $+\mathrm{CT}$, with or without RT

Dismal, most died within $1.5 \mathrm{y}$
CT indicates chemotherapy; EBER, Epstein-Barr virus-encoded RNAs; EMA, epithelial membrane antigen; HARRT, highly active antiretroviral therapy; MZL, marginal zone lymphoma; PTGC, progressive transformation of germinal centers; RT, radiation therapy. 
1 patient was a previously healthy teenager who presented with a localized disease (stage II). The neoplasm she had showed 3 very low proliferation index $(<10 \%)$ as indicated by Ki-67 stain. The patient has been disease free for 17 months after 5 receiving treatment for low-grade B-cell lymphoma. The initial clinicopathologic presentation as well as the disease 7 response to the treatment makes the diagnosis of PBL highly unlikely. The major clinicopathologic features including treatment and prognosis for pediatric MZL, LPL, and PBL were summarized in Table 1. Other differential diagnosis includes atypical marginal zone hyperplasia with $\lambda$ light chain restriction. These cases reported by Attygalle and colleagues all showed $\mathrm{CD} 20^{+} \mathrm{B}$ cells in the expanded marginal zone and follicular hyperplasia. These B cells were IgM, IgD5 positive, and showed high proliferation index by Ki-67 stain. There was no significant plasmacytic differentiation in the 17 reported 6 cases. No evidence of clonality at the genetic level was demonstrated by PCR analysis. ${ }^{20}$ Our case instead showed predominantly IgD-positive, IgM-negative plasmacytoid, and plasma cells with both $\lambda$ chain restriction by 21 immunohistochemical stains and clonality by PCR analysis.

Here, we reported a highly unusual case of clinically stage II neoplasm composed of predominantly IgD-positive, $\lambda$-restricted monoclonal plasmacytoid, and plasma cells, morphologically most compatible with LPL or PCN, in a 13year-old girl with no significant past medical history. The patient was treated per POG9219 protocol for localized NHL and remains in complete remission 17 months after her last chemotherapy. In patients with localized (stage I or II) NHL treated with POG9219, the 5-year event-free survival is up includes complete blood count along with clinical history and physical examination. No imaging is necessary unless a relapse was suspected if the patient was in full remission at the end of therapy (https://members.childrensoncologygroup. org/prot/ProtInfo.asp?ProtocolNum $=$ 9219\&Disease $=$ NHL). Could this case represent an authentic pediatric LPL $C$ or just a MZL with extreme plasmacytic differentiation? In adults, the distinction between B-cell lymphoma with plasmacytic differentiation and $\mathrm{PCN}$ is critical as they require different treatment. In the pediatric population, MZL usually requires only local treatment with long-term follow-up. ${ }^{5}$ For our patient, long-term clinical follow-up may be helpful in the differential diagnosis. Report of other similar cases may also help to answer this question.

Sandlund JT, Downing JR, Crist WM Non-Hodgkin's lymphoma in childhood. N Engl J Med. 1996;334:1238-1248.

2. Setty BA, Termuhlen AM. Rare pediatric non-hodgkin lymphoma. Curr Hematol Malig Rep. 2010;5:163-168. $83.7 \%$, with an overall survival of $96 \%$. The standard follow-
3. Swerdlow SH. Pediatric follicular lymphomas, marginal zone lymphomas, and marginal zone hyperplasia. Am J Clin Pathol. 2004;122(suppl):S98-S109.

4. Rizzo KA, et al. Marginal zone lymphomas in children and the young adult population; characterization of genetic aberrations by FISH and RT-PCR. Mod Pathol. 2010;23:866-873.

5. Taddesse-Heath L, et al. Marginal zone B-cell lymphoma in children and young adults. Am J Surg Pathol. 2003;27:522-531.

6. Claviez A, et al. MALT lymphoma in children: a report from the NHL-BFM Study Group. Pediatr Blood Cancer. 2006;47: 210-214.

7. Gabali A, et al. Pediatric extranodal marginal zone B-cell lymphoma presenting as amyloidosis in minor salivary glands: a case report and review of the literature. $J$ Pediatr Hematol Oncol. 2013;35:e130-e133.

8. Mhawech P, Krishnan B, Shahab I. Primary pulmonary mucosa-associated lymphoid tissue lymphoma with associated fungal ball in a patient with human immunodeficiency virus infection. Archiv Pathol Lab Med. 2000;124:1506-1509.

9. Naithani R, et al. Thymic mucosa-associated lymphoid tissue lymphoma in an adolescent girl. J Pediatr Hematol Oncol. 2012;34:552-555.

10. Menke DM, et al. Primary lymph node plasmacytomas (plasmacytic lymphomas). Am J Clin Pathol. 2001;115: 119-126.

11. Mo JQ, et al. MALT lymphoma in children: case report and review of the literature. Pediatr Dev Pathol. 2004;7:407-413.

12. Rampisela D, Donner LR. An unusual self-limited clonal Mott cell proliferation with lymphoplasmacytic lymphoma-like features in a child with the Wiskott-Aldrich syndrome and Von Recklinghausen's neurofibromatosis. Pathol Res Pract. 2010;206:467-471.

13. Swerdlow SHBF, Pileri SA, Harris NL, et al. Lymphoplasmacytic lymphoma. In: C.E. Swerdlow SH, Harris NL, Jaffe ES, Pileri SA, Stein $\mathrm{H}$, Thiele J, Vardiman JW, eds. WHO Classification of Tumours of Haematopoietic and Lymphoid Tissues. 口: IARC; 2008:194-199.

14. Elenitoba-Johnson KS, Jaffe ES. Lymphoproliferative disorders associated with congenital immunodeficiencies. Semin Diagn Pathol. 1997;14:35-47.

15. McKenna RWKR, Kuehl WM, Grogan TM, et al. Plasma cell neoplasms. In: Swerdlow SH, Harris NL, Jaffe ES, Pileri SA, Stein H, Thiele J, Vardiman JW, eds. WHO Classification of Tumours of Haematopoietic and Lymphoid Tissues. $\mathbf{\square}$ : IARC; 2008:200-213.

16. Stein $\mathrm{H}$, HN, Campo E. Plasmablastic lymphoma. In: Swerdlow SH, Harris NL, Jaffe ES, Pileri SA, Stein H, Thiele $\mathrm{J}$, Vardiman JW, eds. WHO Classification of Tumours of Haematopoietic and Lymphoid Tissues. Lyon: IARC Press; 2008:256-257.

17. Morscio J, et al. Clinicopathologic comparison of plasmablastic lymphoma in HIV-positive, immunocompetent, and posttransplant patients: single-center series of 25 cases and metaanalysis of 277 reported cases. Am J Surg Pathol. 2014;38: 875-886.

18. Thakral C, et al. Plasmablastic lymphoma in an immunocompetent patient. J Clin Oncol. 2009;27:e78-e81.

19. Vaubell JI, et al. Pediatric plasmablastic lymphoma: a clinicopathologic study. Int J Surg Pathol. 2014;

20. Attygalle AD, et al. Atypical marginal zone hyperplasia of mucosa-associated lymphoid tissue: a reactive condition of childhood showing immunoglobulin lambda light-chain restriction. Blood. 2004;104:3343-3348.
113

115 